\title{
New Magnetic Resonance Imaging (MRI) findings in a patient with hypochondroplasia caused by the FGFR3 N540K variant
}

Novos achados de ressonância magnética (RM) em um paciente com hipocondroplasia causada pela variante FGFR3 N540K

Paula Maria Preto MIMURA', José Thiago de Souza de CASTRO², Vinicius de Menezes JARRY², Marcondes Cavalcanti FRANCCA JÚNIOR³, Fabiano REIS²

A 7-year-old boy with hypochondroplasia had neurodevelopmental delay, mild cognitive impairment, subtle motor deficits and without epilepsy. There was no obstetric problem or perinatal impairment. Genetic revealed the p.N540K FGFR3 variant. MRI findings are depicted (Figure 1).
FGFR3 regulates chondrocyte proliferation and differentiation and is instrumental in cortical patterning and neurogenesis ${ }^{1}$. Temporal lobe dysgenesis is common in FGFR3related hypochondroplasia ${ }^{2,3}$. Squared and enlarged lateral ventricles, with reduced peritrigonal white matter (WM) have

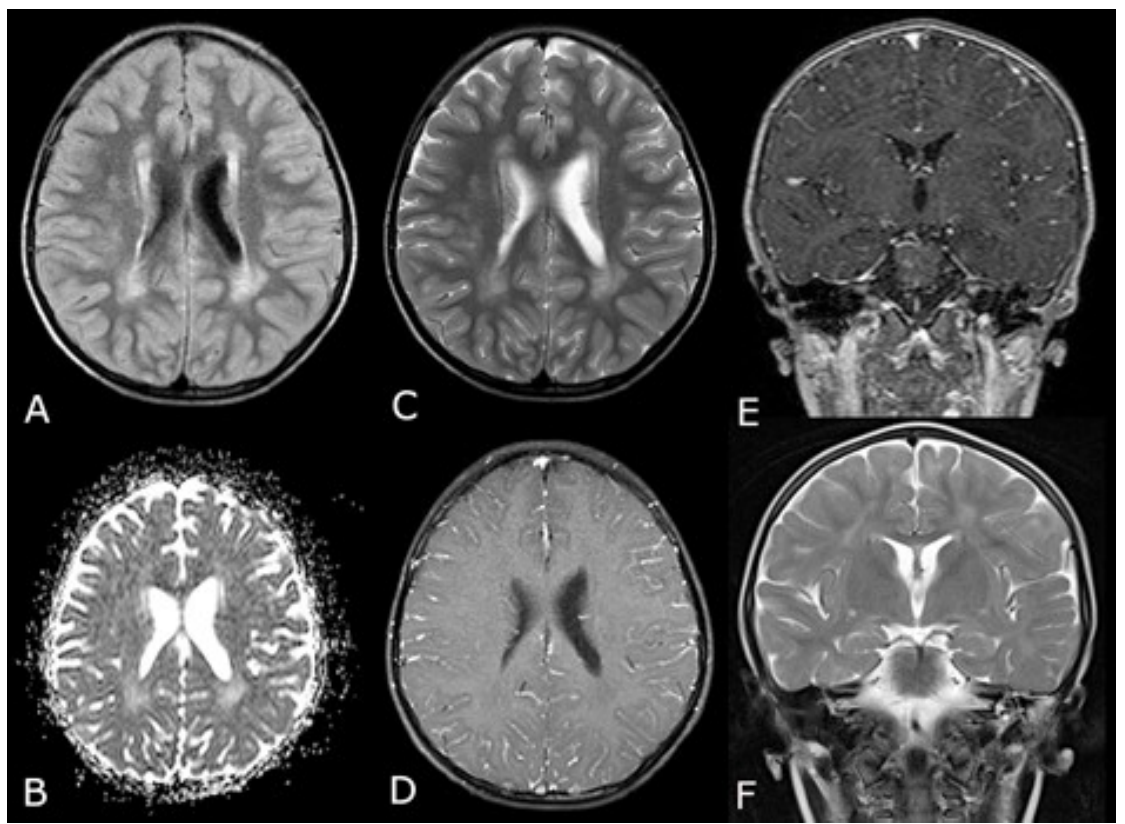

Figure 1. (A) Axial FLAIR-weighted image shows posterior periventricular white-matter hyperintensities. (B) Axial Apparent diffusion coefficient (ADC) map showing hyperintensities in the periventricular white-matter (reflecting absence of restricted diffusion). (C) Axial T2-weighted image shows posterior periventricular white-matter hyperintensities. (D) Axial and (E) Coronal T1-weighted image after gadolinium contrast, demonstrating absence of enhancement. (F) Coronal T2-weighted image without evidence of hippocampal abnormalities.

\footnotetext{
'Pontifícia Universidade Católica de São Paulo, Faculdade de Medicina, Departamento de Reprodução Humana e Infância, Sorocaba, SP, Brazil. ${ }^{2}$ Universidade Estadual de Campinas, Faculdade de Ciências Médicas, Departamento de Radiologia, Campinas, SP, Brazil.

${ }^{3}$ Universidade Estadual de Campinas, Faculdade de Ciências Médicas, Departamento de Neurologia, Campinas, SP, Brazil.

Paula Maria Preto Mimura (D) https://orcid.org/0000-0001-9041-5047; José Thiago de Souza de Castro (D) https://orcid.org/0000-0002-6009-8607; Vinicius de Menezes Jarry (iD https://orcid.org/0000-0002-7391-1193; Marcondes Cavalcanti França Júnior (iD) https://orcid.org/0000-0003-0898-2419; Fabiano Reis (iD) https://orcid.org/0000-0003-2256-4379

Correspondence: Fabiano Reis; Email:fabianoreis2@gmail.com.

Conflict of interest: There is no conflict of interest to declare.

Authors' contribution: VMJ, PMPM and JTSC: acquisition of data and writing the initial drafts of the manuscript; MCFJ: acquisition of data and critical revision; FR: concept, acquisition of data and critical revision of the manuscript for intellectual content.

Received on September 09, 2020; Received in its final form on September 27, 2020; Accepted on October 07, 2020.
}

\section{(cc) BY}


been described ${ }^{2}$, but periventricular WM hyperintensities on T2/FLAIR weighted images, as demonstrated here, were not reported previously.
Such WM lesions expand the neuroimaging signature in FGFR3-related hypochondroplasia.

\section{REFERENCES}

1. Hevner RF. The cerebral cortex malformation in thanatophoric dysplasia: neuropathology and pathogenesis. Acta Neuropathol. 2005 Sep;110(3):208-21.

2. Linnankivi T, Mäkitie O, Valanne L, Toiviainen-Salo S. Neuroimaging and neurological findings in patients with hypochondroplasia and FGFR3 N540K mutation. Am J Med Genet A. 2012;158A(12):3119-25. https://doi.org/10.1002/ajmg.a.35642
3. Philpott CM, Widjaja E, Raybaud C, Branson HM, Kannu P, Blaser S. Temporal and occipital lobe features in children with hypochondroplasia/FGFR3 gene mutation. Pediatr Radiol. 2013 Sep;43(9):1190-5. https://doi.org/10.1007/s00247-013-2684-3 